\title{
Preparation of Polymeric films containing Schiff base as UV-Absorber with Good Resistance against UV-
}

\section{Photoaging}

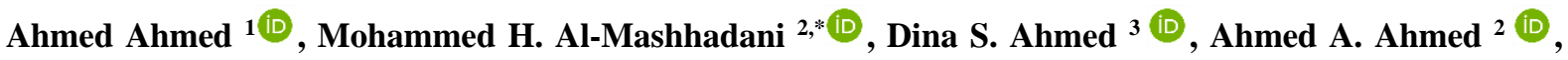 \\ Emad Yousif 2 (D), Rahimi M. Yusop 4 (D) \\ 1 Department of Chemistry, College of Science, Al-Mustansiriyah University, Baghdad, Iraq; \\ dr_ahmedabd@uomustansiriyah.edu.iq (A.A.);
Department of Chemistry, College of Science, Al-Nahrain University, Baghdad, Iraq; \\ Mohammed.mashhadani@ced.nahrainuniv.edu.iq (M.H.); \\ 3 Department of Medical Instrumentation Engineering, Al-Mansour University College, Baghdad, Iraq; \\ dina.saadi@muc.edu.iq (D.S.); \\ 4 School of Chemical Science, Faculty of Science and Technology, University Kebangsaan Malaysia,43600 Bangi, \\ Selangor, Malaysia; hrahimi@ukm.edu.my (R.M.); \\ * Correspondence: mo_chemical@yahoo.com;
}

Scopus Author ID 57201485525

Received: 15.12.2020; Revised: 20.01.2021; Accepted: 24.01.2021; Published: 31.01.2021

\begin{abstract}
To increase the photostability of polystyrene, a new Schiff base has been added to the polystyrene mixture. The polystyrene films have been exposed to ultraviolet light for 300 hours. Schiff's base has been utilized as a long-term polystyrene optical stabilizer against ultraviolet radiation. Schiff base efficiency is widely recognized for using different techniques, including weight loss determinations, infrared spectroscopy, and electron microscopy (SEM) of PS films after 300 hours of irradiation. Polystyrene/Schiff base blend surface morphology was investigated by SEM technique, and the images demonstrated the formation of terrestrial crack materials due to the presence of photostabilizer within the polymer materials. Moreover, the carbonyl group indices were much lower for PS/stabilizer blend than for the blank polymer. The results showed that adding a Schiff base greatly improved the photostability of polystyrene. Furthermore, many unwanted alternations because of the exposure to ultraviolet light were treated by adding the Schiff base compared to the blank polymeric film. The photo-stabilizer absorbs the light and works as a free radical scavenger segment.
\end{abstract}

Keywords: Schiff base; polystyrene; UV radiation; weight loss; films.

(C) 2021 by the authors. This article is an open-access article distributed under the terms and conditions of the Creative Commons Attribution (CC BY) license (https://creativecommons.org/licenses/by/4.0/).

\section{Introduction}

Due to the increasing global interest in environmental problems reasons via traditional polymeric materials, which are complicated to degrade in the natural environment, biodegradable polymers have attracted attention from industrial and academic areas in past decades [1]. Furthermore, this area was highlighted by researchers because of the wide range of applications for plastic materials in the industry, such as in the organic electronic field to fabricate polymeric light-emitting diode or solar cell [2]. These materials are sometimes used as anti-corrosion substances that cover the metals to stop the corrosion [3-4]. Polymers degrade the original structure via irradiation by bonding, free radical production, permanent bonding cleavages, etc., which break down molecules and form saturated and unsaturated groups [5-6]. These processes present what is called deficiency within materials, which are accountable for 
altering the optical, electrical, mechanical, and chemical characteristics of material [7]. In the outdoor environment, the most important severe reason for the degradation is UV radiation, which involves wavelengths that fall, including dissociation energy of the chemical bonds of many of the artificial organic materials utilized in the artwork. Solar radiation and oxygen enhance photosynthetic oxidation reactions on synthetic organic materials. Most of them depend on cleavages of chains and polymers cross-linking reactions utilized as artists' paint materials, like acrylic [8]. Photolysis cause altering in physical and mechanical characteristics of polymers like yellowing, cracking, embrittlement, and hardening of coating films and the changing in the solubility [9-10], and general photolysis processes on polymers begin by absorbing photons from the molecules. The reaction of free radical chains has happened in the propagation stage until new non-radical products are formed by the combinations of radicals in the termination stage. The recombination of macroradicals causes cross-linking within the polymer chains, leading to changing the polymer's physical properties, such as increasing the rigidity and brittleness [11-13]. To inhibit or delay photolysis of the polymer, small molecular photo-stabilizers (such as UV absorbers, scavengers of radical) or inorganic UV screens are added to the polymer matrix during the solubility treatment as the most widely utilized method. Take biodegradable polyesters as an example, UV stabilizers [14-16]. This paper demonstrates the effect of UV irradiation on Schiff base structure doped with polystyrene film by FTIR.

\section{Materials and Methods}

\subsection{Instrumentation.}

Fourier spectra for infrared conversion (FTIR) were reported on the Jasco FT / IR-4200 spectroscope (Tokyo, Japan). PS films morphology was examined using a scanning electron microscope (SEM), Inspect S50 (FEI, Czech Republic). For elements abundance, the Bruker XFlash ${ }^{(B r u k e r, ~ T o k y o, ~ J a p a n) ~ w a s ~ u t i l i z e d ~ h a v e ~ b e e n ~ u t i l i z e d . ~}$

\subsection{Synthesis of Schiff base.}

$1.90 \mathrm{~g}, 6.0 \mathrm{mmol}$ of compound 1 was added to $25 \mathrm{~mL}$ round bottom flask, and then 0.89 g, $6.0 \mathrm{mmol}$ of 4-(dimethylamino)benzaldehyde was added. After that, ethanol (10 mL) was also added as a solvent. Finally, a few drops of glacial acetic acid was added and left the mixture to stir at reflux for 5 hours. After cooling down the mixture, the crude product was recrystallized from ethanol to produce pure target product compound 2.

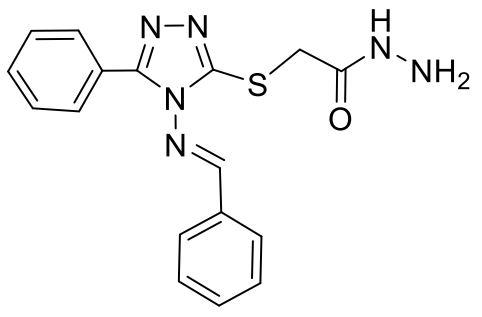

1
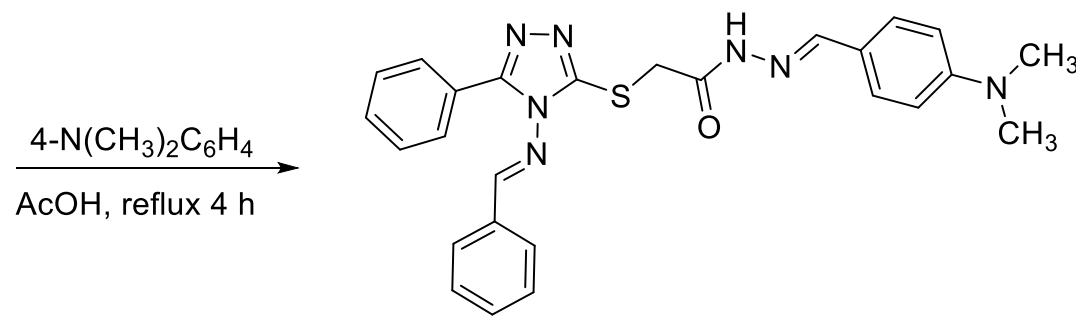

2

Figure 1. Preparation of Schiff base.

\subsection{PS films preparation.}

Films with a thickness of ( $40 \mu \mathrm{m})$ of polystyrene (PS), (polystyrene: Schiff base) (99: $1 \mathrm{w} / \mathrm{w}$ ) were prepared by the technique of pouring the solution using chloroform as a solvent. 
The mixture was stirred for 30 minutes, and then the solution was poured on a glass plate [1821].

\subsection{UV light exposure.}

The prepared polystyrene films were exposed to ultraviolet light for 300 hours at a maximum wavelength of $313 \mathrm{~nm}$ and $6.43 \times 10^{-9} \mathrm{ein} \cdot \mathrm{dm}^{-3} \cdot \mathrm{s}^{-1}$ light intensity. It was used for irradiation of the QUV accelerometer weather-meter (Q -Panel Company, USA).

\section{Results and Discussion}

Schiff base prepared as presented in Figure 1, where brown precipitation achieved $65 \%$ and the melting point range was $110-112^{\circ} \mathrm{C}$. Schiff base structure has been further confirmed by the FTIR spectrum. The FTIR spectrum indicates strong absorption peaks at 1680, 3057, 2922, 1584, 3500, $739 \mathrm{~cm}^{-1}$ assigned to azomethine group $(\mathrm{C}=\mathrm{N}), \mathrm{CH}(\mathrm{Ar}), \mathrm{CH}(\mathrm{Ali}), \mathrm{C}=\mathrm{C}$ (Ar), NH, and C-S in Schiff base, respectively. Figure 2 shows the observed changes in $I_{\mathrm{C}}=\mathrm{O}$. These results confirmed the Schiff base's effective use and, in particular, the Schiff base to enhance photo stabilization for PS films [16].

Changing in PS weight after (300 hours) exposure to UV light is shown in Figure 3. It was evident that loss in the polymer weight was bigger for PS (blank) film when compared to PS and Schiff base blend. The PS film containing compound 2 presented less weight loss than PS (blank) [17].

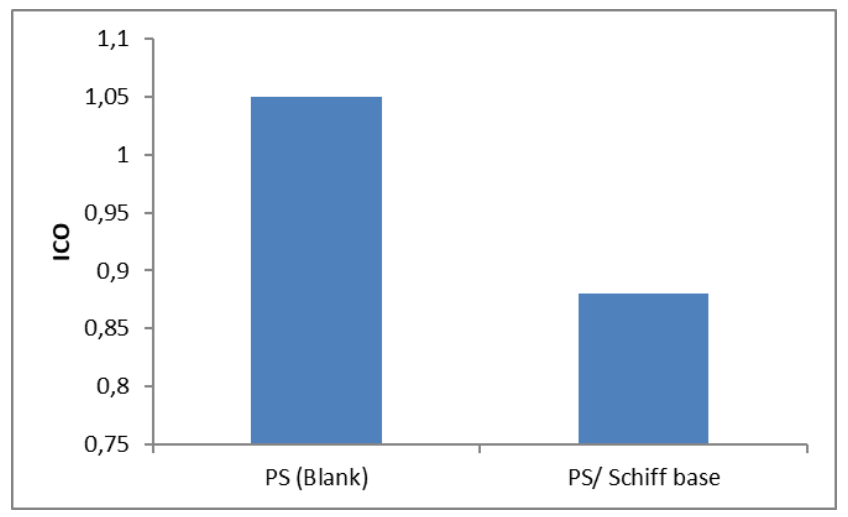

Figure 2. Changing in $I_{\mathrm{C}=\mathrm{O}}$ of polymeric films.

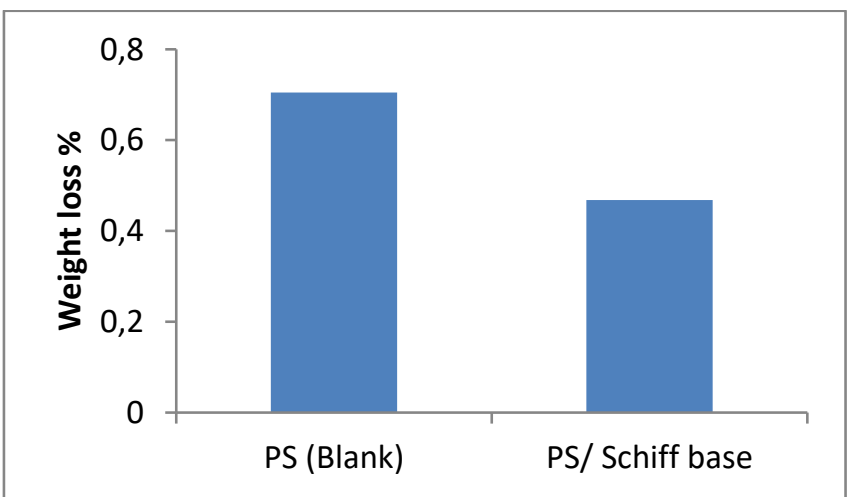

Figure 3. The loss in weight percent changes in the polymeric films.

Use an EDX measurement spot size of $50 \mathrm{~nm}$. The spatial precision of EDX technology is determined by the reaction volume of beam electrons and the sample material and estimated to be approximate. [11]. EDX was used to identify the main elements in polymeric films, in 
principle, and to test films' homogeneity [11]. Figure 4 shows that the PS (blank) film shows strong carbon abundance peaks as a major component.

Figure 5 reveals that the emergence of the new bands associated with nitrogen, sulfur, and oxygen from the Schiff base.

SEM images of PS/Schiff base mixture upon irradiation detected that crack-like polymeric material was fabricated (Figure 6). PS-like terrestrial crack materials have significant improvements in light capture power that have resulted in a high degree of optical stability [11]. The formation of terrestrial-like materials can be related to the incorporation of the Schiff base inside PS surface.

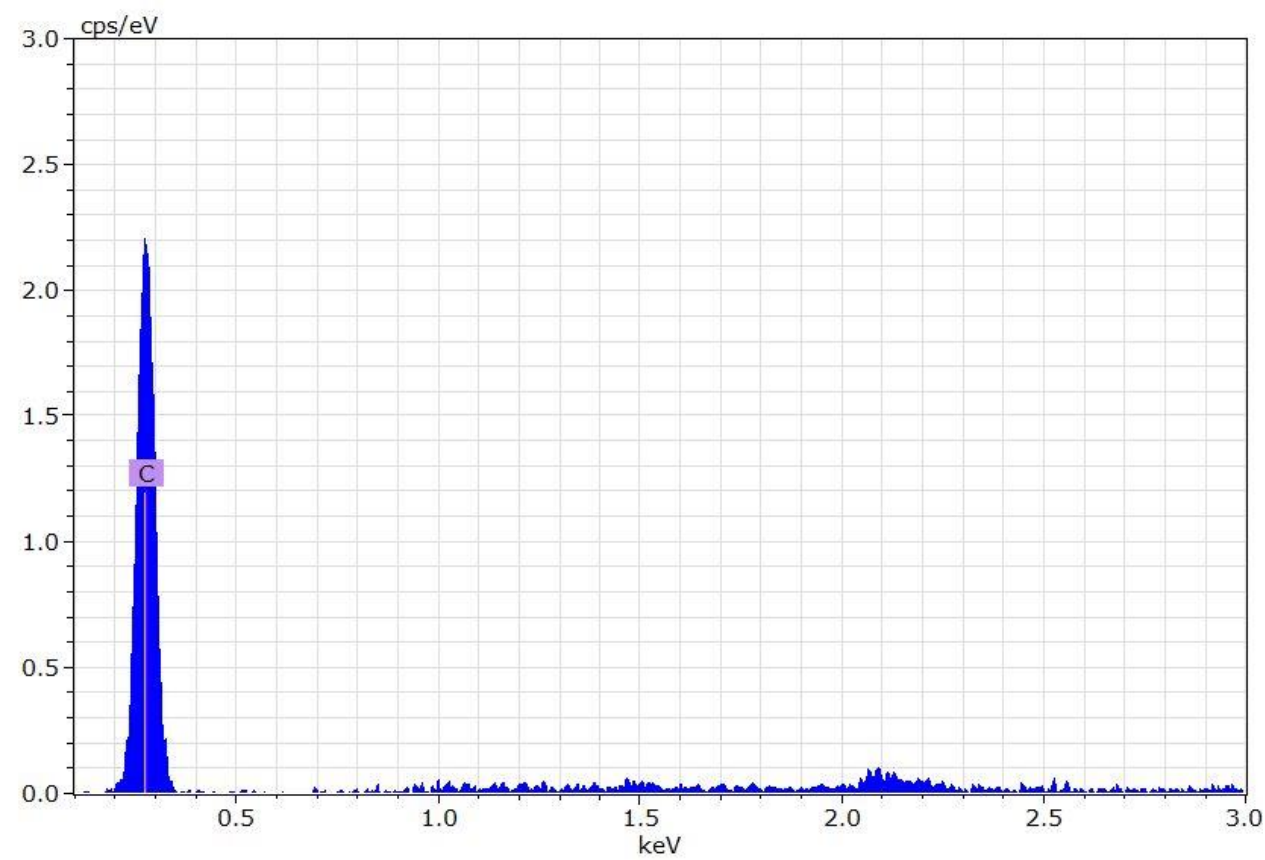

Figure 4. EDX for PS (blank) film.

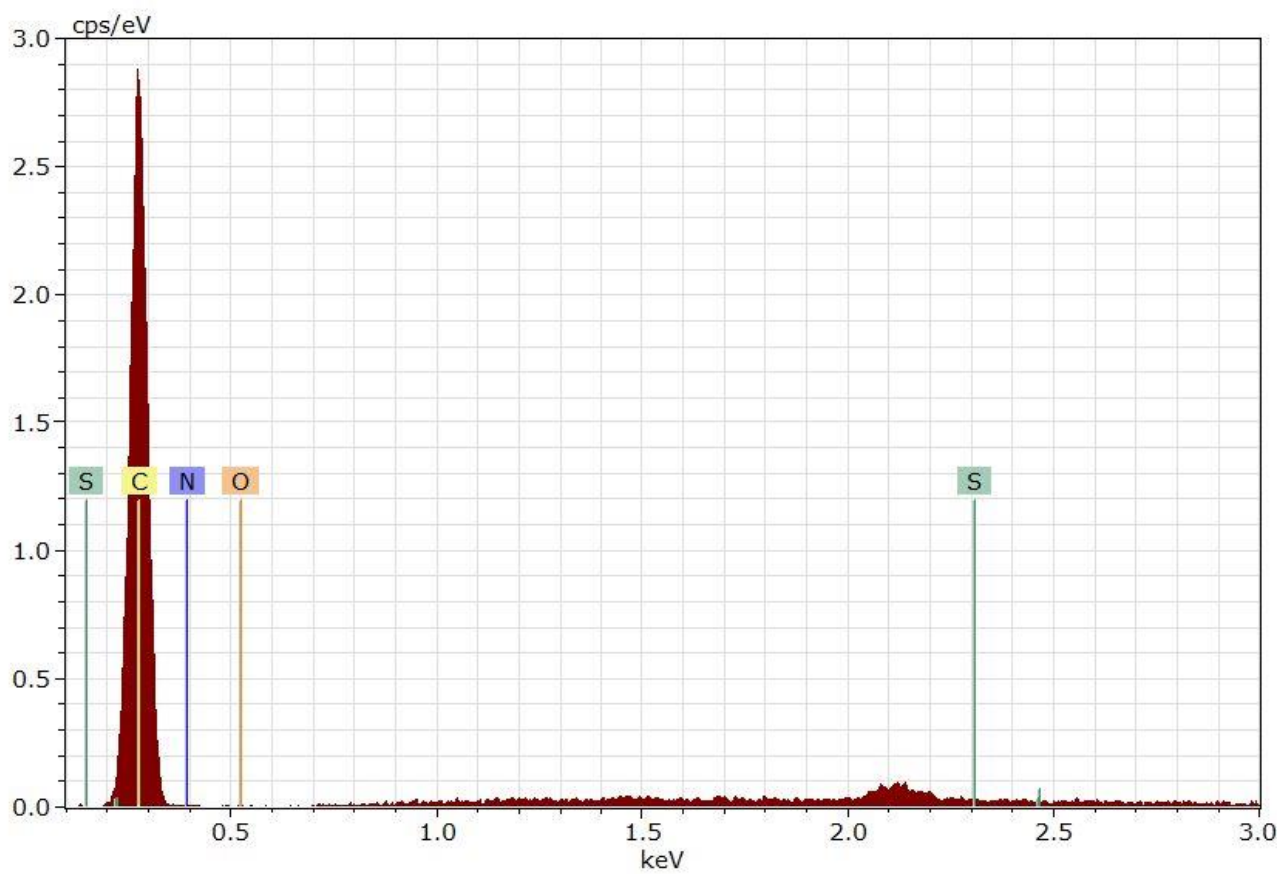

Figure 5. EDX for PS/Schiff base blend. 


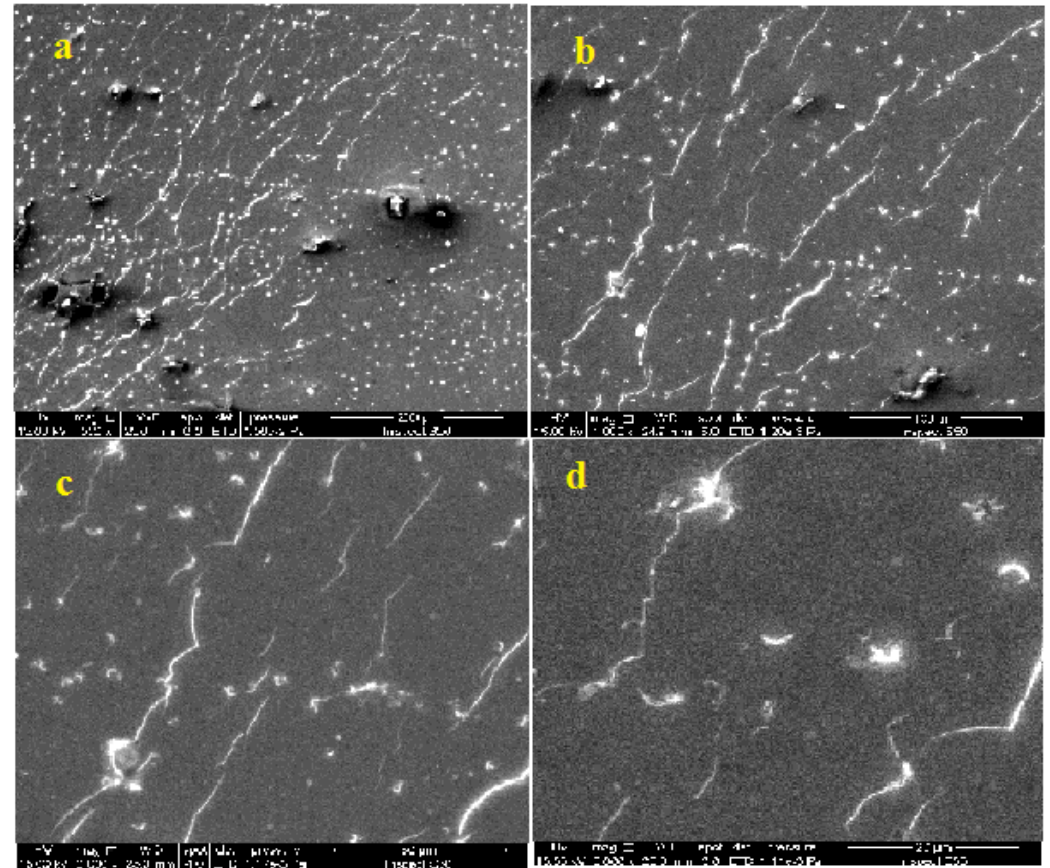

Figure 6. Top view of SEM images of terrestrial cracks-like for PS/Schiff base blend after exposure to UV light (a) $200 \mu \mathrm{m}$. (b) $100 \mu \mathrm{m}$. (c) $50 \mu \mathrm{m}$. (d) $20 \mu \mathrm{m}$.

The surface morphology of prepared polymeric films was also studied by utilizing the optical microscopic image technique. This kind of method is applied to exhibit the homogeneity and roughness of the polymer surface and study the alternation that happens on the polymeric film surface before and after exposure to UV light [18]. Figure 7 shows the microscopic images of polystyrene plus compound 2 before and after irradiation. The polymeric surface of PS after irradiation has more cracks, spots, irregularity, and roughness compare to its surface before exposure to UV light. It has also demonstrated that the PS containing photo-stabilizer (compound 2) film surface after irradiation has less damage compare to blank PS. This is in agreement with other studies that compound 2 is worked as an excellent photo-stabilizer.

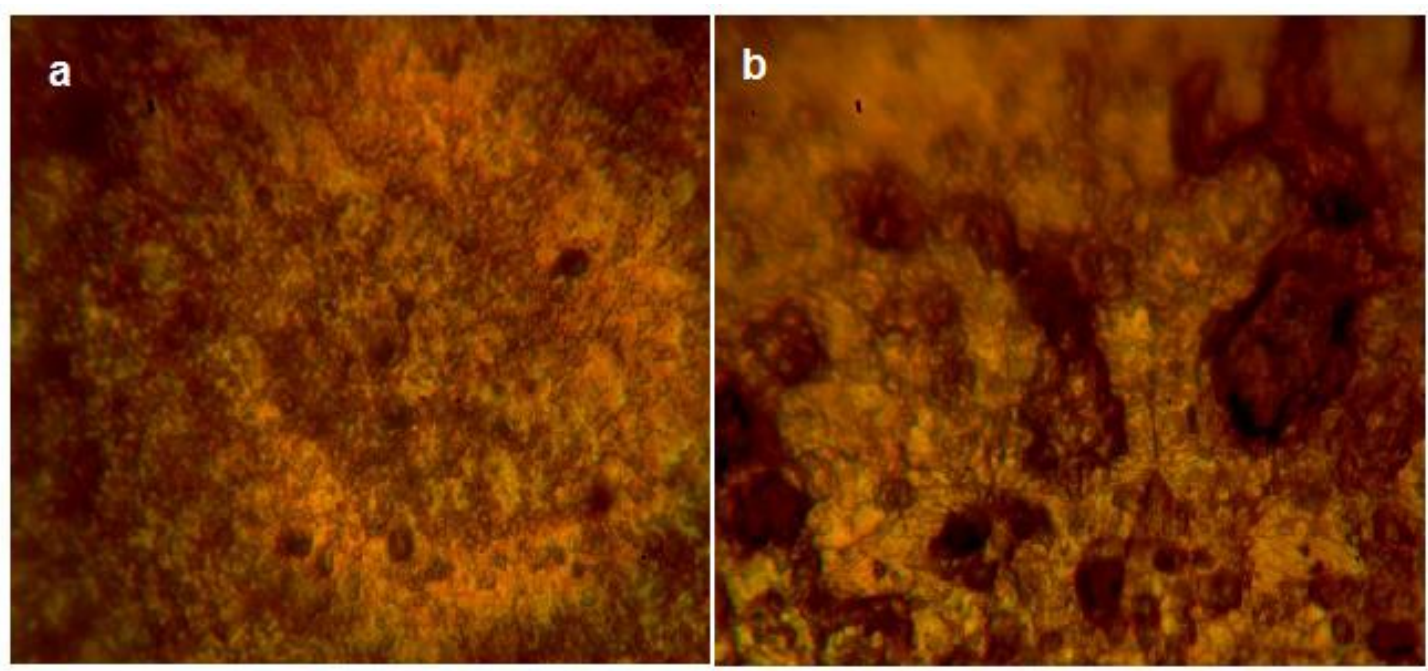

Figure 7. Microscopic images for PS films (a) before irradiation, (b) after irradiation.

\section{Conclusions}

The Schiff base was prepared and utilized as an additive to enhance the physicochemical characteristic of polystyrene. Polystyrene film containing Schiff base is 
irradiated with ultraviolet radiation. An interesting association was observed between the physical and chemical properties of SEM, especially after irradiation.

\section{Funding}

This research received no external funding.

\section{Acknowledgments}

We thank Al-Nahrain University for technical support.

\section{Conflicts of Interest}

The authors declare no conflict of interest.

\section{References}

1. Iwata, T. Biodegradable and Bio-Based Polymers: Future Prospects of Eco-Friendly Plastics. Angewandte Chemie International Edition 2015, 54, 3210-3215, https://doi.org/10.1002/anie.201410770.

2. Ghosh, S.; Alghunaim, A.S.; Al-mashhadani, M.H.; Krompiec, M.P.; Hallett, M.; Perepichka, I.F. 4,5Diazafluorene co-oligomers as electron deficient light-emitting materials and selective fluorescence sensors for mercury (II) cations. J. Mater. Chem. C. 2018, 6, 3762-3773, https://doi.org/10.1039/C7TC05051H.

3. Pratap Rao, D. A review on versatile applications of novel Schiff bases and their metal complexes. Letters in Applied NanoBioScience 2019, 8, 675-681, https://doi.org/10.33263/LIANBS84.675681.

4. Ahmed, W.A.; Al-Mashhadani, M.H.; Abdallh, M.; Hussain, Z.; Yousif, E. Eco-friendly green corrosion inhibitors in overview. Research Journal in Advanced Sciences 2020, 1, 7-16.

5. Ahmed, A.A.; Al-mashhadani, M.H.; Hussain, Z.; Mohammed, S.A.; Yusop, R.M.; Yousif, E. Inhibition of Corrosion: Mechanisms and Classifications an Overview. JOPS 2020, 25, 1-9, https://doi.org/10.29350/qjps.2020.25.2.1072.

6. Ahmed, A.A.; Al-mashhadani, M.H.; Hashim, H.; Ahmed, D.S.; Yousif, E. Morphological, Color Impact and Spectroscopic Studies of New Schiff Base Derived From 1,2,4-Triazole Ring. Prog. Color Colorants Coat 2021, 14, 27-34, https://doi.org/10.30509/pccc.2021.81664.

7. Khalaf, M.; Fadhil, Z.; Al-Mashhadani, M. H.; Abdallh, M.; Bufaroosha, M.; Majeed, A.; Salih, N.; Yousif, E. PVC Films Performance Stabilized By Dibutyltin (IV) Complex For Sustainable Environment. Journal of Physics: Conference Series 2020, 1664, https://doi.org/10.1088/1742-6596/1664/1/012072.

8. Mohammed, S.A.; Najim, L.H.; Al-mashhadani, M.H.; Ismael, M.; Hamad, B.A.; Noaman, R.; Ibraheem, H.; Ahmed, D.S.; Yousif, E. Morphological and Photodecomposition Rate Constant Study of PVC Films Doped with Sulfadiazine Tin (IV) Complexes. Science Letters 2020, 14, 88-96.

9. Tanu, S.; Sanjeev, A.; Shyam, K.; Mittal, V.; Kalsi, P.; Manchanda, V. Effect of gamma irradiation on the optical properties of CR-39 polymer. Journal of Materials Science 2007, 42, 1127-1130, https://doi.org/10.1007/s10853-006-0516-7.

10. Learner, T. Modern Paints Uncovered. The Getty Conservation Institute, Los Angeles, 2008.

11. Jablonski, E.; Learner, T.; Hayes, J.; Golden, M. The Conservation of Acrylic Emulsion Paintings: a Literature Review. Tate Papers, Tate's Online Research Journal, 2004.

12. Bufaroosha, M.; Salih, N.; Hadi, A. G.; Ahmed, D.S.; Al-mashhadani, M.H.; Yousif, E. The Effect of UV Aging on the Structure of PVC in the Presence of Organotin (IV) Compounds. ANJS 2020, 23, 57-61, https://doi.org/10.22401/ANJS.23.1.08.

13. Dintcheva, N.T.; La Mantia, F.P. Durability of a starch-based biodegradable polymer. Polymer Degradation and Stability 2007, 92, 630-634, https://doi.org/10.1016/j.polymdegradstab.2007.01.003.

14. Coelho, C.; Hennous, M.; Verney, V.; Leroux, F. Functionalisation of polybutylene succinate nanocomposites: from structure to reinforcement of UV-absorbing and mechanical properties. Rsc Advances 2012, 2, 5430-5438, https://doi.org/10.1039/C2RA20579C.

15. Ahmed, A. A.; Ahmed, D. S.; El-Hiti, G. A.; Alotaibi, M. H.; Hashim, H.; Yousif E. SEM morphological analysis of irradiated polystyrene film doped by a Schiff base containing a 1,2,4-triazole ring system. Applied Petrochemical Research 2019, 9, 169-177, https://doi.org/10.1007/s13203-019-00235-6.

16. Smith, S.H.; Taylor, L.T. Extraction of various additives from polystyrene and their subsequent analysis. Chromatographia 2002, 56, 165-169, https://doi.org/10.1007/BF02493206.

17. Tunali-Akbay, T.; Kahraman M.V.; Oktay, B.; İpekci, H.; Kayaman-Apohan, N. Bioactivated poly (vinyl alcohol) /poly(acrylic acid) based nanofiber for high-performance membrane techniques. Letters in Applied NanoBioScience 2020, 9, 819 - 823, https://doi.org/10.33263/LIANBS91.819823. 
18. Yousif, E.; Haddad, R.; El-Hiti, G.A.; Yusop, R.M. Spectroscopic and photochemical stability of polystyrene films in the presence of metal complexes. J. Taibah Univ. Sci 2017, 11, 997-1007, https://doi.org/10.1016/j.jtusci.2017.03.002.

19. Rabie, S.T.; Ahmed, A.E.; Sabaa, M.W.; Abd El-Ghaffar, M.A. Maleic diamides as photostabilizers for polystyrene. J. Ind. Eng. Chem 2013, 19, 1869-1878, https://doi.org/10.1016/j.jiec.2013.02.033.

20. Watheq, B.; Yousif, E.; Al-Mashhadani, M.H.; Mohammed, A.; Ahmed, D.S.; Kadhom, M.; Jawad, A.H. A Surface Morphological Study, Poly(Vinyl Chloride) Photo-Stabilizers Utilizing Ibuprofen Tin Complexes against Ultraviolet Radiation. Surfaces 2020, 3, 579-593, https://doi.org/10.3390/surfaces3040039.

21. Karakas, A.; Elmali, A.; Ünver, H.; Svoboda, I. Nonlinear optical properties of some derivatives of salicylaldimine-based ligands. J. Mol. Struct $2004, \quad$ 702, $103-110$. https://doi.org/10.1016/j.molstruc.2004.06.017.

22. Eftekhari, S.; Foroughifar, N.; Khajeh-Amiri, A.; Hallajian, S. Synthesis and characterization of polymeric nanocomposites based on poly-melamine-paraformaldehyde and superparamagnetic silicon dioxide loaded Iron(III) oxide core-shell composite magnetic nanoparticles. Letters in Applied NanoBioScience 2020, 9, 914 - 918, https://doi.org/10.33263/LIANBS91.914918.

23. Pandeya, S.N.; Sriram, D.; Nath, G.; DeClercq, E. Synthesis, antibacterial, antifungal and anti-HIV activities of Schiff and Mannich bases derived from isatin derivatives and N-[4-(40-chlorophenyl)thiazol-2-yl] thiosemicarbazide. Eur. J. Pharm. Sci 1999, 9, 25-31, https://doi.org/10.1016/S0928-0987(99)00038-X.

24. Shivarama, B.; Veerendra, B.; Shivananda, M.K.; Poojary, B. Synthesis characterization and anticancer activity studies on some Mannich bases derived from 1,2,4-triazoles. Eur. J. Med. Chem 2003, 38, 759-767, https://doi.org/10.1016/S0223-5234(03)00128-4.

25. Pouretedal, H. R.; Damiri, S.; Karami, Z. Increasing of photostability of HNS explosive in the presence of UV photostabilizers. Defence Technology 2020, in press, https://doi.org/10.1016/j.dt.2020.02.001.

26. Nakatani, H.; Kyan, T.; Urakawa, Y.; Novel Recycling System of Polystyrene Water Debris with Polymer Photocatalyst and Thermal Treatment. J Polym Environ 2020, 28, 3279-3288, https://doi.org/10.1007/s10924-020-01976-5.

27. Nikafshara, S.; McCracken, J.; Dunnec, K.; Nejad, M. Improving UV-Stability of epoxy coating using encapsulated halloysite nanotubes with organic UV-Stabilizers and lignin. Progress in Organic Coatings Available online 9 December 2020, In Press, https://doi.org/10.1016/j.porgcoat.2020.105843.

28. Krishnan, T.; Salida Wan Mansor, W. Photocatalytic Degradation of Dyes by TiO2 Process in Batch Photoreactor. Letters in Applied NanoBioScience 2020, 9, 1502-1512, https://doi.org/10.33263/LIANBS94.15021512.

29. Xiao, L.; Zhao, Y.; Jin, B.; Zhang, Q.; Chai Z.; Peng, R. Synthesis of novel ultraviolet stabilizers based on [60]fullerene and their effects on photo-oxidative degradation of polystyrene. Fullerenes, Nanotubes and Carbon Nanostructures 2020, 28, 465-473, https://doi.org/10.1080/1536383X.2019.1703695. 